\title{
ANÁLISE COMPARATIVA DOS MÉTODOS DE CLASSIFICAÇÃO DA VEGETAÇÃO NDVI E ANÁLISE POR COMPONENTES PRINCIPAIS EM UMA IMAGEM RAPIDEYE
}

José Irley Ferreira Júnior ${ }^{1}$

\section{Resumo}

O uso do sensoriamento remoto tem crescido relevantemente e contribuído de forma multidisciplinar. Várias áreas utilizam-se desta ferramenta na busca de automatização de rotinas que antes eram feitas manualmente e com isso economizando tempo e custo. $\mathrm{Na}$ área ambiental isso caracteriza em mapeamentos agilizados, diminuição de trabalhos de campo desnecessários entre outros. Contudo não se descarta a importância do trabalho de campo uma vez que as análises de dados em sensoriamento remoto precisam do conhecimento in loco. Esse trabalho foi desenvolvido somente em etapa de escritório utilizando-se de um fragmento de cena de imagem Rapideye. O objetivo foi realizar uma análise comparativa no mapeamento da vegetação densa através das técnicas de Índice de Vegetação por Diferença Normalizada - NDVI e Análise por Componentes Principais - CPA. Após a geração e classificação de cada imagem (NDVI e CPA), e análise das matrizes de confusão e coeficiente de Kappa, chegou-se à conclusão que CPA e NDVI apresentaram resultados similares no mapeamento da vegetação.

Palavras-chave:sensoriamento remoto, NDVI, CPA, vegetação densa

\begin{abstract}
The use of remotesensinghasgrown and contributedmaterially in a multidisciplinaryway. Severalareas of the tool are used in automatedsearchroutinesthatwerepreviouslydonemanually and thussaving time and cost. In theenvironmentalareathatfeaturesstreamlined in mappings, decreaseunnecessaryfieldworkamongothers. But do notrule out theimportance of fieldworksincetheremotesensing data analysisneedthe spot knowledge. Thisworkwascarried out only in office stepusing a fragment of RapidEyeimagescene. The objectivewastoconduct a comparativeanalysis in mappingthedensevegetationthroughNormalizedDifferenceVegetation Index - NDVI and Principal ComponentAnalysis - CPA. Aftergeneration and classification of eachimage (NDVI and CPA), and analysis of confusionmatrix and Kappacoefficientwasreachedtheconclusionthat CPA and NDVI showed similar results in themapping of vegetation.
\end{abstract}

Keywords:remotesensing, NDVI, CPA, dense vegetation

1 (UFMG) jose.geografo@gmail.com 


\section{1- INTRODUÇÃO}

Com a crescente necessidade de se preocupar com os aspectos ambientais em relação a atuação antrópica, metodologias são criadas para monitoramento de atividades que trazem impacto direto e indireto ao meio ambiente. Devido a amplitude territorial, em muitos casos não é possível ter um acompanhamento presencial de forma efetiva, o que demandaria maior custo e tempo. Pensa-se nesse sentido, formas de aquisição de dados a distância de maneira que os mesmos possam ser tratados e transformados em informação. Neste propósito, destaca-se a tecnologia de sensoriamento remoto. Segundo Teresa Florenzano (2011, p. 9):

O termo sensoriamento refere-se à obtenção de dados por meio de sensores instalados em plataformas terrestres, aéreas (balões e aeronaves) e orbitais (satélites artificiais). O termo remoto, que significa distante, é utilizado porque a obtenção é feita à distância, ou seja, sem o contato físico entre o sensor e objetos na superfície terrestre...

O sensoriamento remoto (SERE) tem contribuído para diversos vieses no monitoramento ambiental, principalmente no que diz respeito a vegetação. $O$ estudo das mudanças florestais constitui um setor de trabalho cada vez mais importante para gestores governamentais e particulares. Observa-se que "os dados de satélites formam uma alternativa interessante, pois devido à sua capacidade de acessar grandes áreas, permitem otimizar os trabalhos de campo, respeitando recursos financeiros escassos" (JANOTH et al, 2007, p. 99). Senso assim, o monitoramento de áreas extensas se torna viável no âmbito da vegetação, contudo é necessário enfatizar que a tecnologia não elimina a necessidade do trabalho de campo uma vez que este é primordial para entender a realidade construída no estande digital.

A tecnologia de SERE se utiliza principalmente da energia solar, pois é através da resposta espectral desta energia refletida que é possível realizar o mapeamento dos alvos. Dentro do espectro do visível, no qual o ser humano enxerga, a vegetação apresenta-se na cor verde, pois é nesta faixa que a energia é mais refletida, pois é a menor utilizada no processo de fotossíntese. Todavia, a faixa do espectro eletromagnético que a vegetação sadia mais reflete é na região do infravermelho próximo. A Figura 1 mostra faixas do espectro eletromagnético e a reflectância de alguns alvos. 


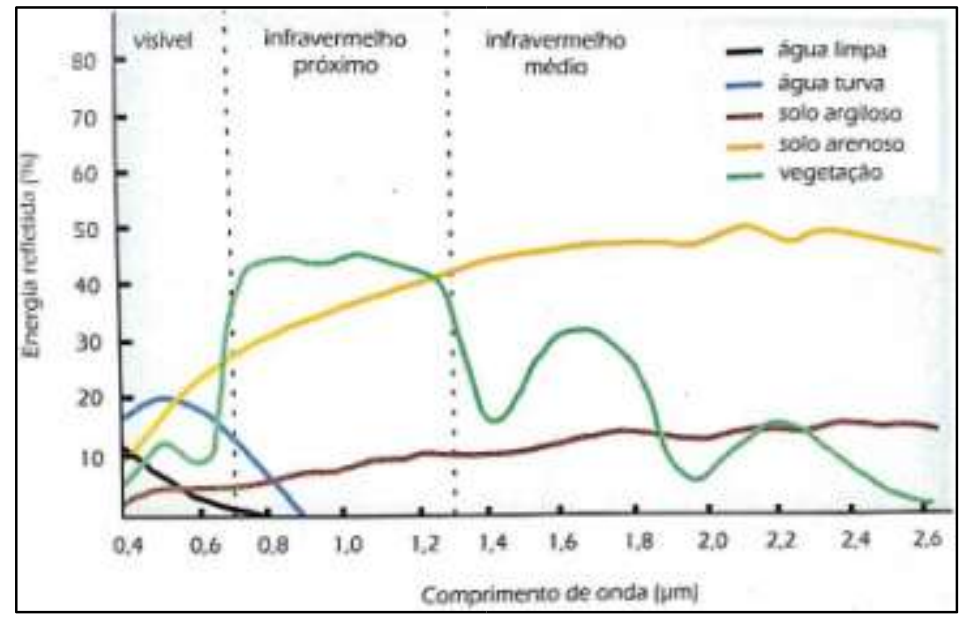

Figura 1. Curva espectral da vegetação, da água e do solo (FLORENZANO, 2011, p. 12)

Através da Figura 1 é possível identificar a curva espectral da vegetação elevada na região do infravermelho próximo. Utilizando-se destes dados, criam-se métodos de mapeamento da vegetação que são introduzidas no sensoriamento remoto. Pode-se citar alguns deles como o Índice de Vegetação da Razão Simples (SimpleRatio - SR), Índice de Vegetação Perpendicular (Perpendicular Vegetation Index - PVI), Índice de Vegetação Ajustado para o Solo (SoilAdjustedVegetation Index - SAVI) e o Índice de Vegetação da Diferença Normalizada (NormalizedDifferenceVegetation Index - NDVI). Estas técnicas estatísticas possuem uma característica em comum sendo a utilização de duas faixas do espectro eletromagnético, vermelho e infravermelho próximo.

A fundamentação destes índices está no comportamento antagônico da reflectânciada vegetação nas duas regiões (vermelho - visível e infravermelho próximo). Neste caso, quanto maior for a densidade da cobertura vegetal em determinada área, menor será a reflectância na região do visível devido à maior oferta de elementos fotossintetizantes. Por outro lado, maior será a reflectância na região do infravermelho próximo, por causa do espalhamento múltiplo da radiação eletromagnética nas diferentes camadas das folhas (PONZONI e al, 2012, p. 87). A Figura 2 a seguir mostra o contraponto dos valores de reflectância na região do visível e do infravermelho próximo. 


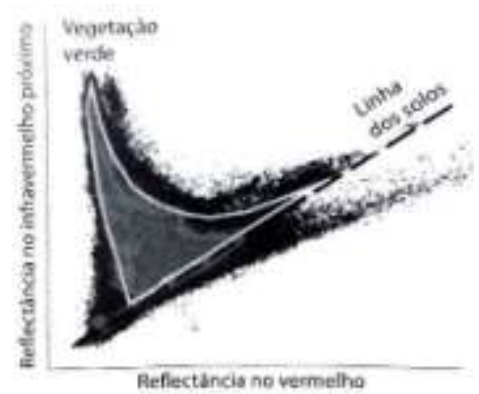

Figura 2. Infravermelho próximo X visível (PONZONI et al, 2012, p. 88)

Outro método que tem em comum a utilização destas faixas do espectro eletromagnético é a Análise por Componentes Principais (Components Principal Analisys - CPA). É um método estatístico utilizado em diversas áreas do conhecimento, mas que pode ser adaptado para o mapeamento da vegetação. Em linhas gerais a CPA procura eliminar a repetição de dados presente nas bandas espectrais de forma que seja possível resumir as informações de interesse em um conjunto menor.

Dentre os índices de vegetação mais utilizados, destaca-se o NDVI que será o alvo de uma análise comparativa entre a CPA de forma a verificar o método que possui melhor resposta enquanto precisão para o mapeamento da vegetação em um fragmento de imagem Rapideye. Portanto, para melhor entendimento do que será discutido é importante abordar de forma mais detalhada as técnicas de NDVI e CPA.

\section{2- ÍNDICE DE VEGETAÇÃO POR DIFERENÇA NORMALIZADA - NDVI}

O NDVI normaliza a razão simples para o intervalo de $-1 \mathrm{a}+1$. O limite inferior para alvos terrestres é zero (0) e o limite superior é aproximadamente 0,8. A Equação 1 mostra o cálculo deste índice:

$\mathrm{NDVI}=(\mathrm{NIR}-\mathrm{RED}) /(\mathrm{NIR}+\mathrm{RED})$

Onde:

NIR = FRB no Infravermelho próximo;

RED $=$ FRB no vermelho;

FRB $=$ Fator de Reflectância Bidirecional. 
De acordo com Flávio Ponzoniet al (2012, p. 90):

...o NDVI é utilizado para construir perfis sazonais e temporais das atividades da vegetação, permitindo comparações interanuais desses perfis. O perfil temporal do NDVI tem sido utilizado para detectar atividades sazonais e fenológicas, duração do período de crescimento, pico de verde, mudanças fisiológicas das folhas e períodos de senescência.

Atualmente o NDVI é amplamente utilizado em áreas como estudos climáticos e culturas agrícolas e florestais. Todavia, este índice possui limitações como: pontos de saturação que se manifestam de formas diferenciadas nas faixas espectrais do vermelho e infravermelho próximo; interferência atmosférica que também se diferencia nestas duas faixas espectrais; posicionamento do centro e largura de cada banda, tanto no vermelho quanto no infravermelho próximo, que varia de acordo com os sensores (PONZONI et al, 2012, p. 90). O Resultado do NDVI apresenta uma imagem em níveis de cinza onde os tons mais claros estão relacionados aos valores mais elevados enquanto os mais escuros, os valores mais baixos (Figura 3).

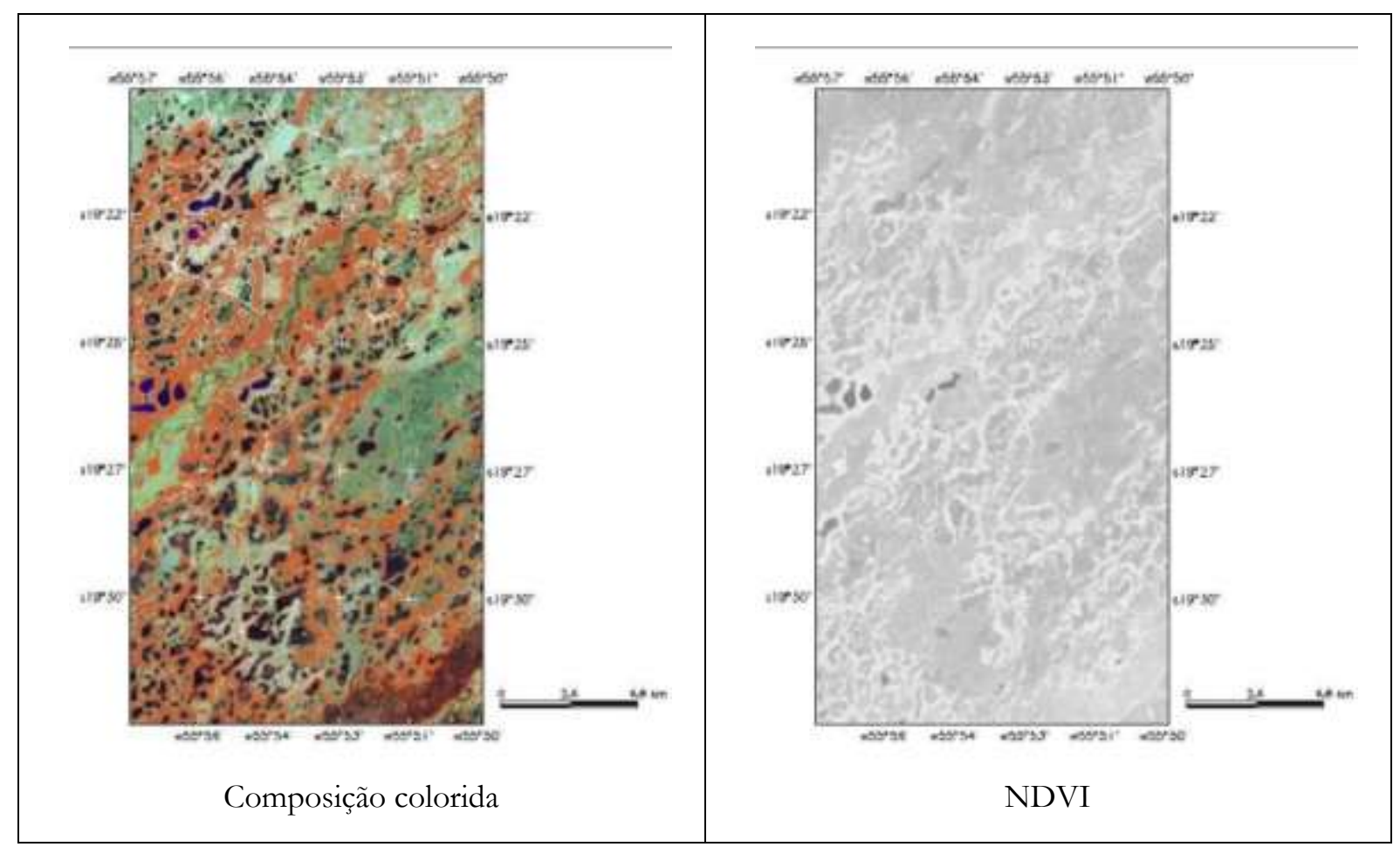

Figura 3. Composição colorida (ETM3-azul, ETM4-vermelho e ETM5-verde) do Pantanal de Nhecolândia e imagem NDVI correspondente a essa cena. (PONZONI et al, 2012, p. 92).

O NDVI está sujeito a interpretações equívocas devido a influência sofrida pelas áreas de sombra. Pode-se ocorrer, por exemplo, falsa interpretação entre florestas primárias e secundárias se a rugosidade da vegetação na primeira causar muitas sombras e neste caso a saturação será maior na segunda. O resultado do NDVI pode variar de acordo com as características espectrais 
e radiométricas dos sensores e por este motivo é importante verificar estes aspectos que servirão de extração de dados para o cálculo desse índice.

Mesmo com limitações, o NDVI é um dos índices mais utilizados no mundo e que como todo método, deve ser verificado suas vantagens e desvantagens de acordo com o objetivo do estudo que se pretende realizar.

\section{3- ANÁLISE POR COMPONENTES PRINCIPAIS - CPA}

Em uma imagem multiespectral, as bandas individuais possuem tendências de serem altamente correlacionadas. Por este motivo, informações contidas nas mesmas podem se apresentar de forma redundante. As correlações podem ser causadas devido a sombras na topografia, da sobreposição das janelas atmosféricas entre bandas adjacentes e do comportamento espectral do objeto.

A correlação entre duas bandas é avaliada quando dada a intensidade de um determinado pixel em uma delas, pode-se inferir com certa aproximação a intensidade do pixel correspondente da outra imagem. Sendo duas imagens idênticas, diz-se que as mesmas são 100\% correlacionadas, sendo uma imagem oposta a outra, considera-se que são $-100 \%$ correlacionadas. Didaticamente em um conjunto de $\mathrm{N}$ imagens de entrada, posteriormente a aplicação da $\mathrm{CPA}$, vai produzir um conjunto de $\mathrm{N}$ imagens de saída que será de acordo com o número de bandas espectrais utilizadas. Essas imagens não possuem correlação entre si, sendo o conjunto de saída chamados de primeira componente principal (CP1), o segunda CP2 e assim por diante.

Para aplicação da CPA, não é necessário utilizar todas as bandas de uma imagem, isto é, usa-se apenas as bandas que possuem resposta espectral relevante para o objetivo do estudo. No caso da identificação da vegetação, pode-se considerar as bandas do vermelho e infravermelho próximo assim como é feito nos índices de vegetação. Desta forma serão geradas duas componentes principais, a CP1que possuirá informações que são comuns as duas bandas e a CP2 que conterá a feição espectral mais significante do conjunto. Este novo conjunto de imagens, que são independentes, são resultados da transformação derivada da matriz de covariância (Equação 2).

(Equação 2)

Segundo

$$
\operatorname{Cov}\left(X_{1}, X_{2}\right)=\frac{\sum_{i=1}^{n} X_{n} \cdot X_{12}-\frac{\left(\sum_{i=1}^{n} X_{A}\right)\left(\sum_{i=1}^{n} X_{i 2}\right)}{n}}{n-1}
$$

Adriano Venturieri 
(2007, p. 76), "tal técnica de transformação envolve uma rotação e uma translação num hipotético espaço de atributos espectrais, produzindo novas variáveis conhecidas como componentes ou eixos" (Figura 4).

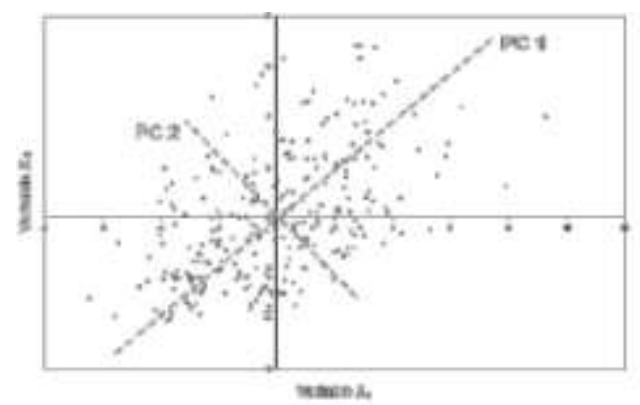

Figura 4. Comportamento da transformação por componentes principais em uma distribuição bivariada

A CP1 é a direção de maior variância na nuvem p-dimensional de pontos. A CP2 está na direção da próxima maior variância, condicionalmente a zero com variância com PC1.

A utilização da técnica de componentes principais vem crescendo no meio acadêmico e com o objetivo de se encontrar metodologias que retratem melhor a realidade, esta técnica será comparada ao NDVI. A análise será feita em um fragmento de imagem Rapideye.

\section{4- MATERIAIS E MÉTODOS}

Para a realização deste trabalho, foram necessários os seguintes dados:

- Fragmento da imagem Rapideye 2011- Órbita/Ponto 345/217, cedida pelo IEF-MG;

- Camada máscara para corte da cena;

- Camada ponto com a localização de Belo Horizonte;

- Camada contendo o limite de Minas Gerais;

- Mapa base para realizar a análise comparativa;

A área de estudo compreende o fragmento de uma imagem Rapideye localizada a norte da Serra de Ouro Branco, município de Ouro Branco, Minas Gerais. A Figura 5 mostra a localização. 


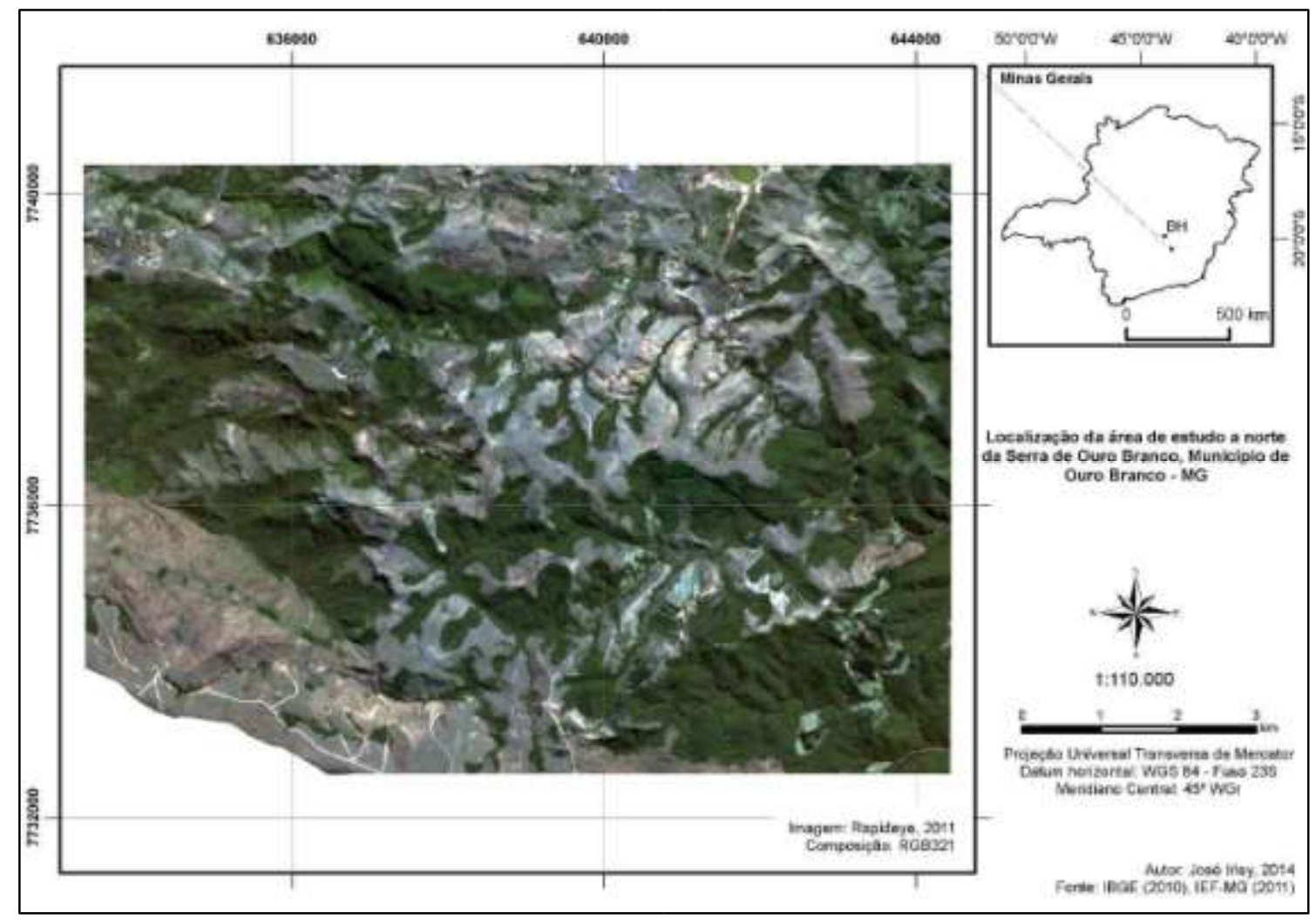

Figura 5. Localização da área de estudo

Esta área foi escolhida devido à presença de vegetação densa e outras condicionantes que podem ser fatores limitantes já mencionados para cada método analisado (CPA e NDVI). A partir disso pode-se verificar o comportamento de classificações em situações diversas.

Referente ao Rapideye, atual Black Bridge, este caracteriza-se por um sistema composto por cinco satélites de sensoriamento remoto idênticos e que possuem mesma órbita. A faixa de cobertura de coleta de imagens é de $77 \mathrm{~km}$ de largura e $150 \mathrm{~km}$ de extensão. A Tabela 1 mostra as características do sensor. 
Tabela 1. Características dos satélites Rapideye

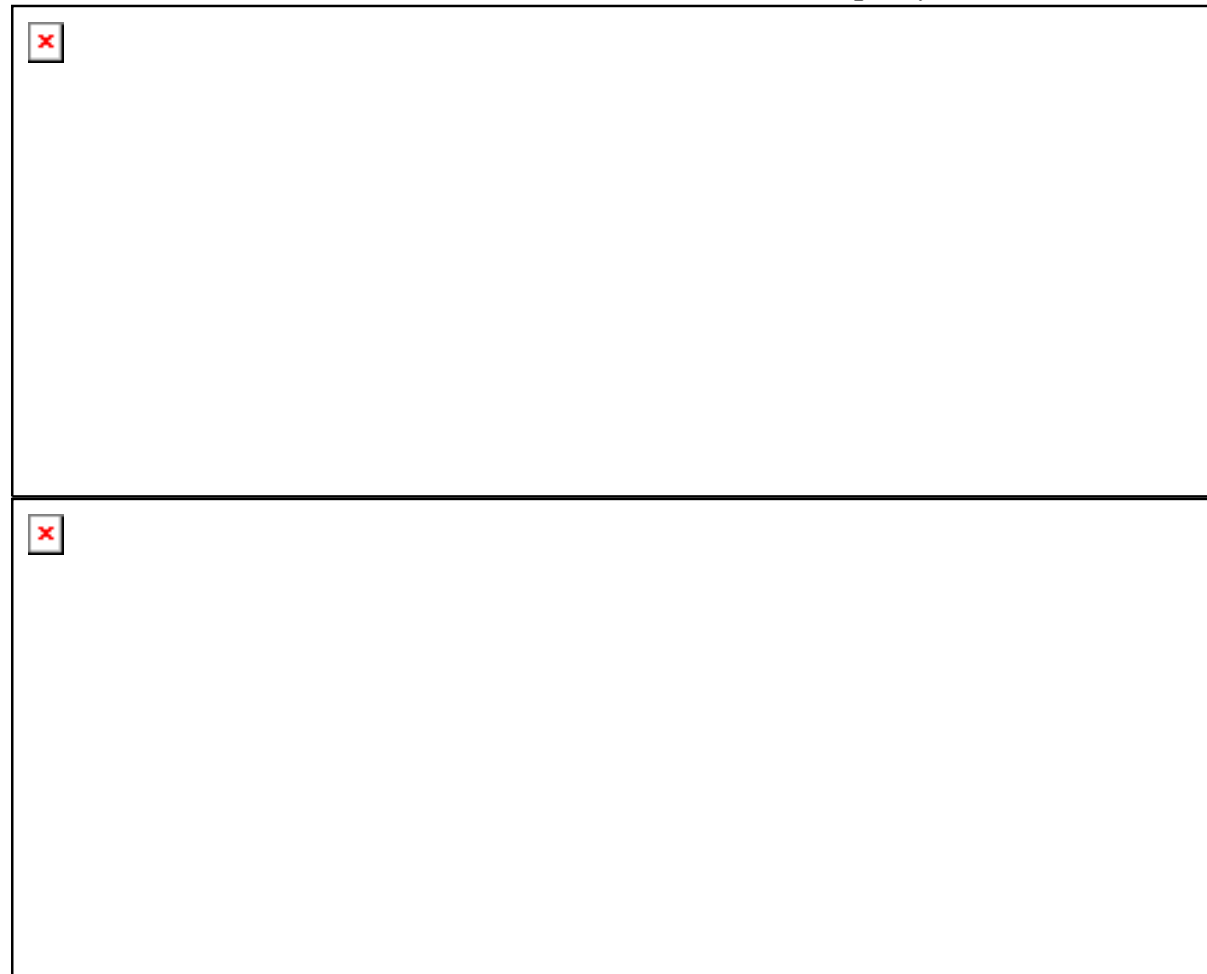

Fonte: Adaptado de Rapideye, 2014.

Primeiramente, a imagem Rapideye foi reprojetada para o datum WGS 84 UTM zona 23S. Em seguida foi empilhada no software ENVI $4.7 \mathrm{com}$ as bandas 1, 2, 3, 4 e 5. Posteriormente a imagem foi recortada no software Quantum GIS versão 2.2 para a área demonstrada no mapa de localização. O resultado foi carregado no Spring 5.2.7 para realizar os procedimentos de geração do NDVI e CPA. Todavia, para que ocorresse a comparação em momento oportuno, foi feita uma classificação modelo no intuito de retratar a realidade da vegetação densa. Este modelo serviu para gerar o coeficiente de Kappa para a classificação feita a partir da componente principal e NDVI. A chave de interpretação e o resultado desta classificação modelo consta na Tabela 2 e Figura 6 respectivamente a seguir.

Tabela 2. Chave de interpretação para classificação modelo

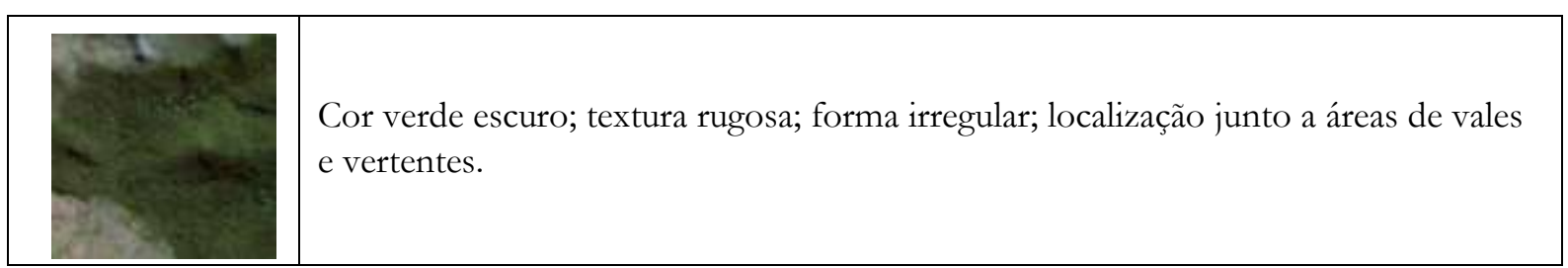




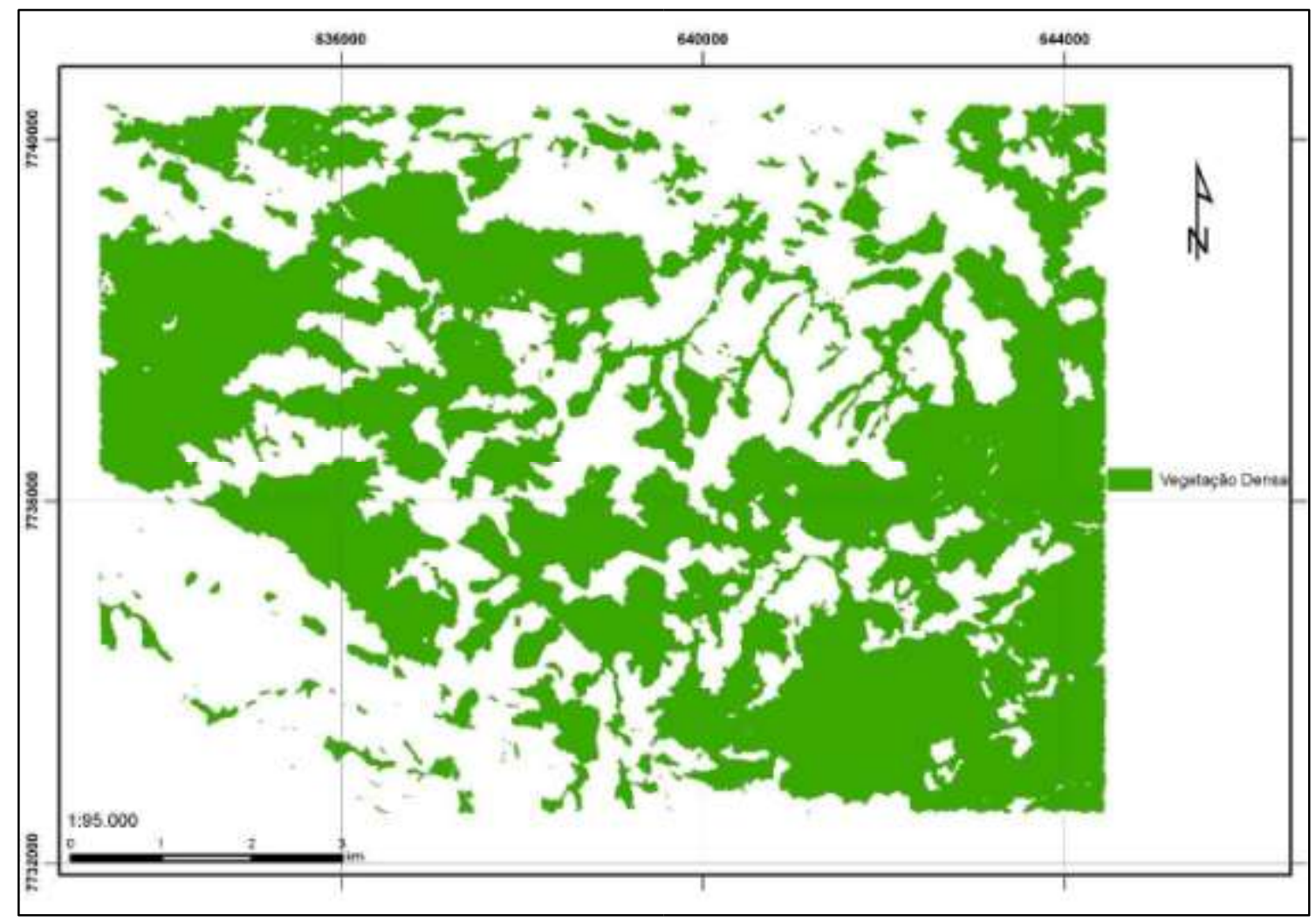

Figura 6. Classificação modelo - mapa base

\section{5- RESULTADOS E DISCUSSÕES}

Para melhor percepção e interpretação da imagem no visível, foram contrastados os canais vermelho, verde e azul na composição RGB321. O primeiro passo foi a geração do NDVI sendo que no Spring este procedimento se constitui em uma tarefa simplificada através da ferramenta "Operações Aritméticas" do menu "Imagem". O Spring entende esta operação da seguinte forma:

$\mathrm{C}=$ Ganho $^{*}((\mathrm{~A}-\mathrm{B}) /(\mathrm{A}+\mathrm{B}))+$ Offset

Onde:

$\mathrm{A}=$ banda infravermelho próximo

$\mathrm{B}=$ banda vermelho

Os fatores de ganho (multiplicativo) e o off-set(aditivo) são valores não obrigatórios na equação. Todavia eles podem ser utilizados para melhorar a qualidade de contraste da imagem. A definição destes valores depende da habilidade do usuário, na definição das operações entre bandas e das características espectrais das bandas utilizadas. (SPRING, 2014). Neste trabalho não 
foram atribuídos valores para esses dois fatores. O resultado do NDVI se apresentou da seguinte forma conforme Figura 7.

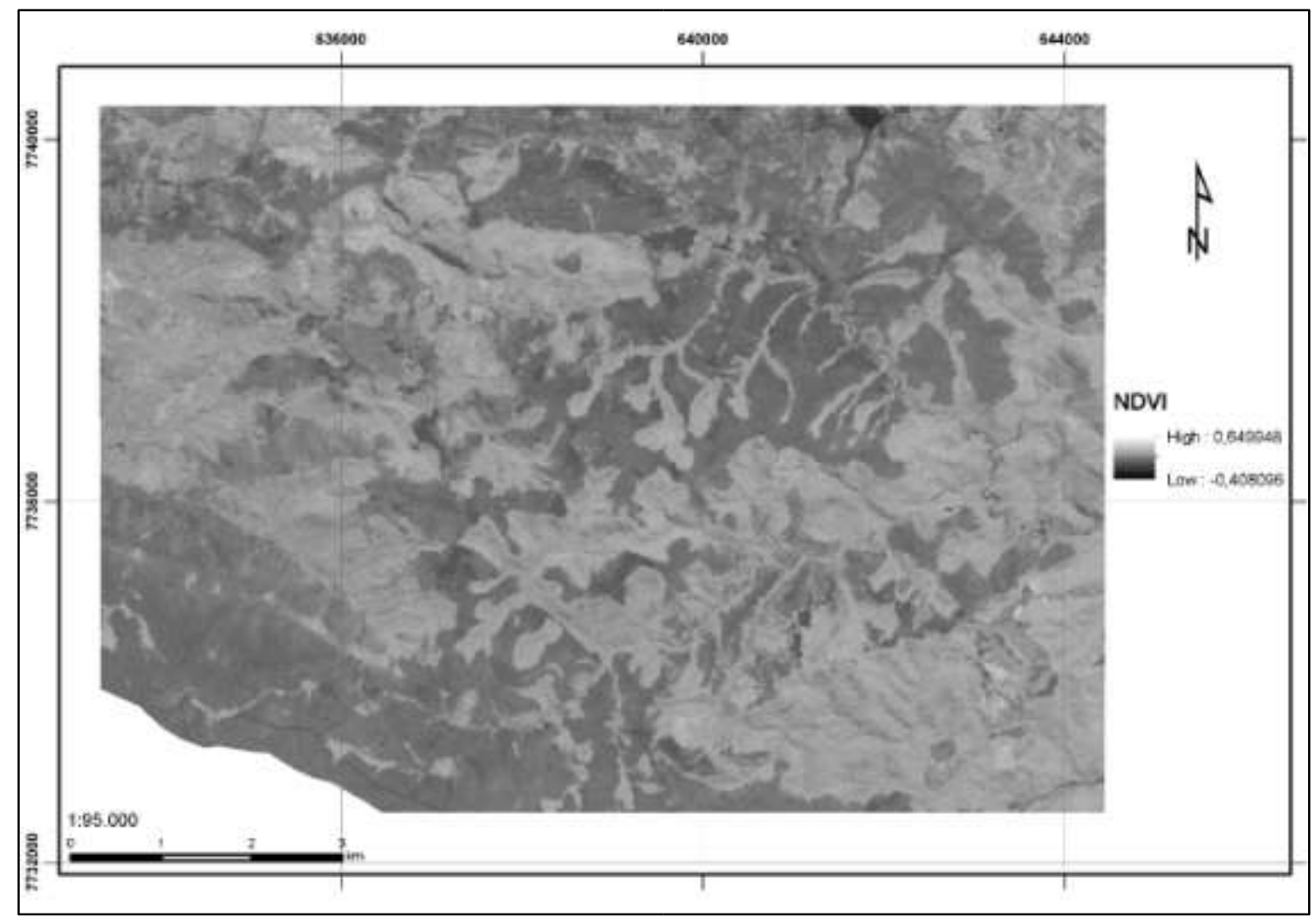

Figura 7. NDVI da imagem Rapideye

Observa-se que os valores normalizados da imagem possuem seu período de 0,408096 a 0,649946, sendo que o valor negativo significa menor presença da vegetação, portanto mais escuro e o valor positivo, quanto mais próximo de 1 , evidencia maior presença da vegetação, neste caso, cor clara.

Após a geração do NDVI, partiu-se para o processamento da imagem empilhada através do método de componentes principais. Da mesma forma que no NDVI, o software utilizado também foi o Spring. A ferramenta acionada foi "Componentes Principais". Neste processo verificou-se as componentes principais em relação as duas bandas do satélite Rapideye, sendo a 3 (vermelho) e 4 (infravermelho próximo), resultando na CP2, utilizada para mapeamento da vegetação densa que contém a feição espectral mais significante do conjunto(Veja a Figura 8). 


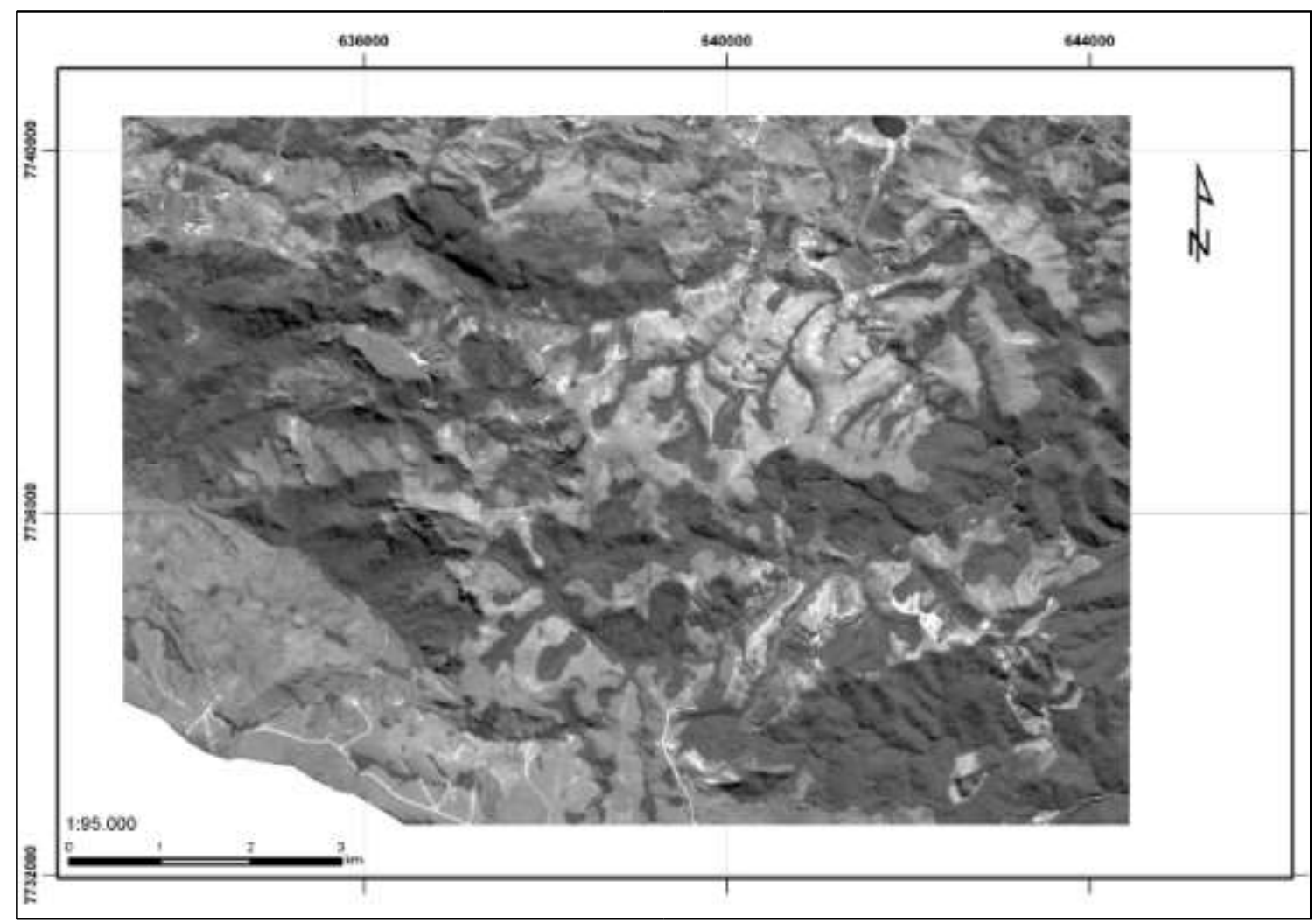

Figura 8. Componente Principal 2

A imagem gerada mostra diferença em relação ao NDVI que ao contrário do mesmo, destacou feições ligadas ao solo na cor clara, contudo existindo diferenciação entre a vegetação que se encontra mais escura. Através da geração da componente principal, foi possível verificar parâmetros demonstrados nas tabelas a seguir.

Tabela 3. Média e Variância

\begin{tabular}{ccc}
\hline Plano de Informação & Média & Variância \\
Rapideye_3 & 2165.00 & 723786.87 \\
Rapideye_4 & 2909.69 & 480139.89 \\
\hline
\end{tabular}

Tabela 4. Autor-Valor e Porcentagem

\begin{tabular}{ccc}
\hline Componentes Principais (PC) & Auto-valor & Porcentagem (\%) \\
P1 & 1127611.82 & 93.66 \\
P2 & 76314.95 & 6.34 \\
\hline
\end{tabular}


Tabela 5. Matriz de Covariância

\begin{tabular}{ccc}
\hline Plano de Informação Rapideye_3 & Rapideye_4 \\
Rapideye_3 & 723786.87 & 511336.79 \\
Rapideye_4 & 511336.79 & 480139.89
\end{tabular}

Tabela 6. Matriz de Correlação

\begin{tabular}{ccc}
\hline Plano de Informação Rapideye_3 & Rapideye_4 \\
Rapideye_3 & 1.000 & 0.867 \\
Rapideye_4 & 0.867 & 1.000 \\
\hline
\end{tabular}

Tabela 7. Matriz de Auto-Vetores

\begin{tabular}{ccc} 
Plano de Informação Rapideye_3 & Rapideye_4 \\
Rapideye_3 & 0.78 & -0.62 \\
Rapideye_4 & -0.62 & 0.78 \\
\hline
\end{tabular}

Os auto-valores expressam a quantidade de variância explicada por cada componente e os auto-vetores são os coeficientes de ponderação associado às variáveis utilizadas nas equações de transformação. (SANTOS et al, 2010, p. 145)

Através da Tabela 7 é possível verificar que a componente 1 (P1) explica 93,66\% da variação e a componente 2 (P2) explica 6,34\% da variação. No Spring, o novo conjunto de imagens que são independentes entre si, é o resultado da transformação derivada da matriz de covariância dos valores originais. Conforme já mencionado, o número de componentes principais é igual ao número de imagens, neste caso duas, sendo ordenados de forma decrescente em função da variação do nível de cinza. Portanto, irá ser considerada a P1 como CP2 onde consta a maior variância. A Tabela 5 mostra que realmente não existe correlação entre as bandas 3 e 4 .

Com a geração da imagem NDVI e PC2, passou-se para o procedimento de classificação das mesmas. A classificação utilizada foi pelo método não-supervisionado utilizando o algoritmo K-médias. Este se caracteriza por um algoritmo de agrupamento fixado a priori. O objetivo do K-médias é minimizar a variabilidade interna do agrupamento que é dimensionada pela função soma das distâncias (erros) entre cada pixel e o centro ao qual é alocado. Este procedimento 
solicita dois parâmetros, sendo o número de temas (quantidade de classes - K) e iterações (entre os grupos). Os valores utilizados para estes parâmetros para ambas imagens foram de: Tema - 8; Iteração - 1. Após a classificação pelo K-médias, foi feito um mapeamento de classes para cada imagem informando ao software qual classe pertencia a feição de vegetação densa. Os resultados das classificações para NDVI e PC2 constam nas figuras 9 e 10 a seguir.

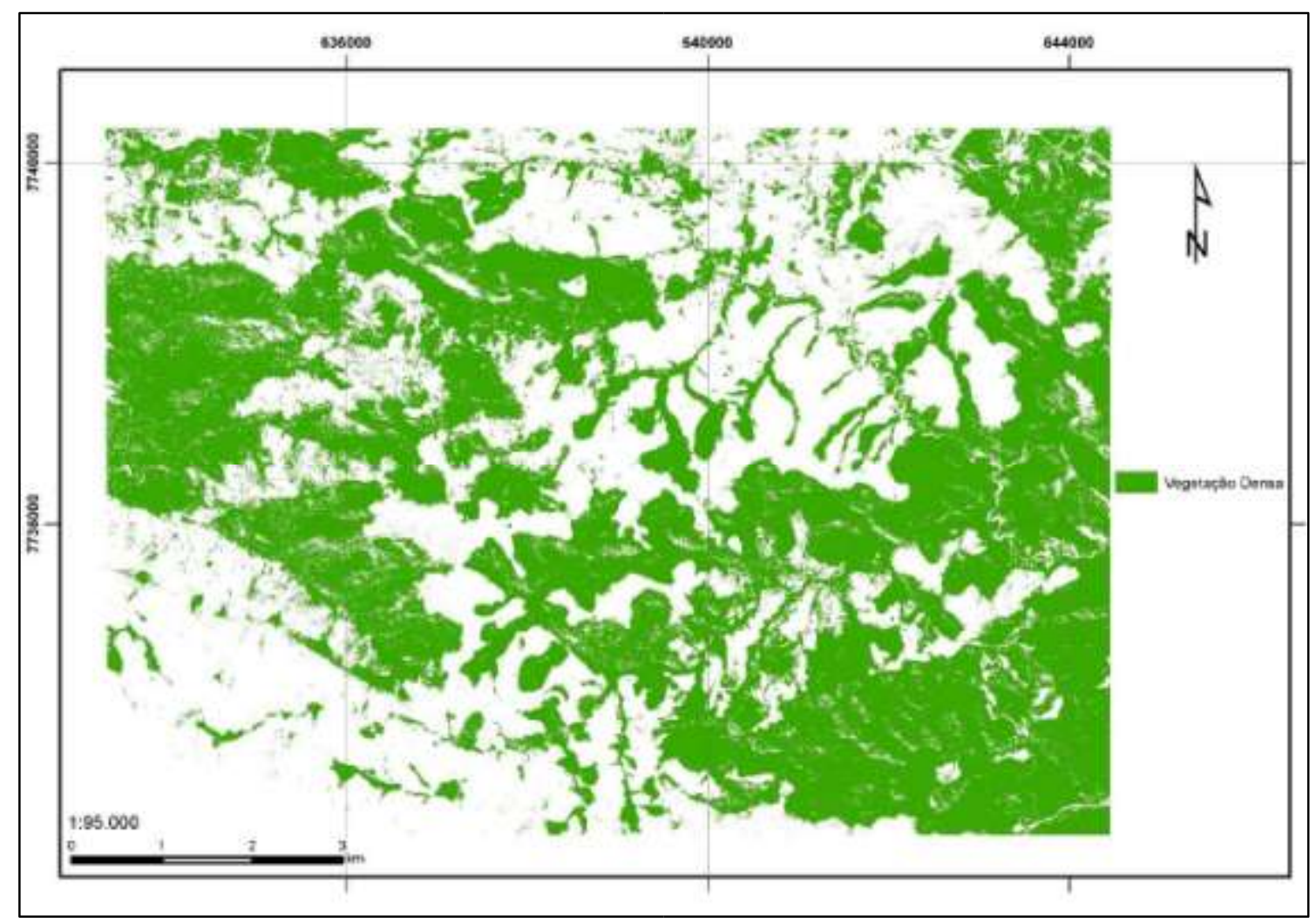

Figura 9. Classificação a partir da imagem NDVI

A Figura 9 demonstra a vegetação densa identificada pela classificação da imagem NDVI. Visualmente percebe-se que ocorreram poucas diferenças se comparada ao mapa base. Ao sobrepor com a imagem de composição RGB321, percebe-se que o NDVI foi sensível a áreas de sombra, conforme explicitado no embasamento teórico, e por isso deixando de classificar algumas áreas. As principais diferenças podem ser vistas em áreas que possuem continuidade na vegetação e ondulações no relevo. O porte arbóreo da vegetação também exerceu influência, pois é outro fator que também causa sombras. Isso demonstra que é interessante a utilização do NDVI em imagens que praticamente necessitam estar sem sombras, ou seja, o sol no seu zênite. A classificação também pode ser avaliada conforme dados da matriz de confusão NDVI X Mapa Base. Veja a Tabela 8. 
Tabela 8. Matriz de Confusão - NDVI X Mapa Base (F = Floresta; NF= Não Floresta)

\begin{tabular}{cccc|cccc}
\hline \multicolumn{9}{c}{ Matriz de Confusão } \\
\cline { 1 - 2 } Classe & F & NF & Total & Classe & F & NF & Total \\
F & 1529590 & 228570 & 1758160 & F & 88,17 & 13,09 & 50,51 \\
NF & 205223 & 1517177 & 1722400 & NF & 11,83 & 86,91 & 49,49 \\
Total & 1734813 & 1745747 & 3480560 & Total & 100 & 100 & 100 \\
\hline
\end{tabular}

A Tabela 8 se caracteriza em uma matriz quadrada que expressa o número de unidades de amostra, sendo no primeiro caso em pixels e no segundo em percentual. Verificase que 205223 pixels de NF foram classificados em F, representando 11,83\%. A classe NF também possui pixels classificados em F representando 13,09\%. Outros parâmetros podem ser observados a partir da Tabela 9 a seguir.

Tabela 9. Erros e Acurácia - NDVI X Mapa Base

\begin{tabular}{ccccc}
\hline \multicolumn{5}{c}{ Erros } \\
\hline Classe & Comissão (\%) & Omissão (\%) & Comissão (pixel) & Omissão (pixel) \\
F & 13 & 11,83 & $228570 / 1758160$ & $205223 / 1734813$ \\
NF & 11,91 & 13,09 & $205223 / 1722400$ & $228570 / 1745747$ \\
\hline \multicolumn{5}{c}{ Acurácia } \\
\hline Classe & Acur. Prod.(\%) & á́rio (\%) & Acur. Prod.(pixel) & Usuário (pixel) \\
F & 88,17 & 87 & $1529590 / 1734813$ & $1529590 / 1758160$ \\
NF & 86,91 & 88,09 & $1517177 / 1745747$ & $1517177 / 1722400$ \\
\hline
\end{tabular}

Através da Tabela 9 é possível verificar a probabilidade de erros e acurácia daclassificação através de duas vertentes: produtor e usuário (comissão e omissão). Referente aos erros de comissão em F, verifica-se que existe a probabilidade de 13\% de que NF tenha sido classificado erroneamente nesta classe. Este valor é conseguido dividindo o número de pixels incorretos em dada categoria (NF classificados em F), pelo número total de pixels classificados nesta categoria. A classe NF possui a probabilidade $11,91 \%$ de $\mathrm{F}$ ter sido incorporado a sua classe. Esses dois primeiros erros referem-se a comissão (usuário), ou seja, são indicativos de probabilidade de um pixel classificado no mapa de referência representar esta categoria no campo. Referente ao erro 
de omissão (produtor), número de pixels incorretos em dada categoria pelo número de pixels da coluna correspondente, observa-se que a probabilidade de NF ter sido classificado em F é de $11,83 \%$ e de $\mathrm{F}$ ter sido classificado em NF é de 13,09\%.

A acurácia é calculada inversamente aos erros. O procedimento é feito através da classificação dos pixels corretos em dada categoria dividindo pelo total da coluna correspondente, caracterizando-se em acurácia de comissão. A acurácia de omissão é feita dividindo o número de pixels corretos em dada categoria pelo total de pixels classificado na mesma. A acurácia de comissão de $\mathrm{F}$ foi de $88,17 \%$ e comissão de $87 \%$. Em relação a NF a comissão foi de $86,91 \%$ e omissão de 88,09\%.

A acurácia global deste mapeamento foi de $87,54 \%$. Este valor é conseguido somando o número de pixels na diagonal da matriz quadrada pelo número total de pixels.

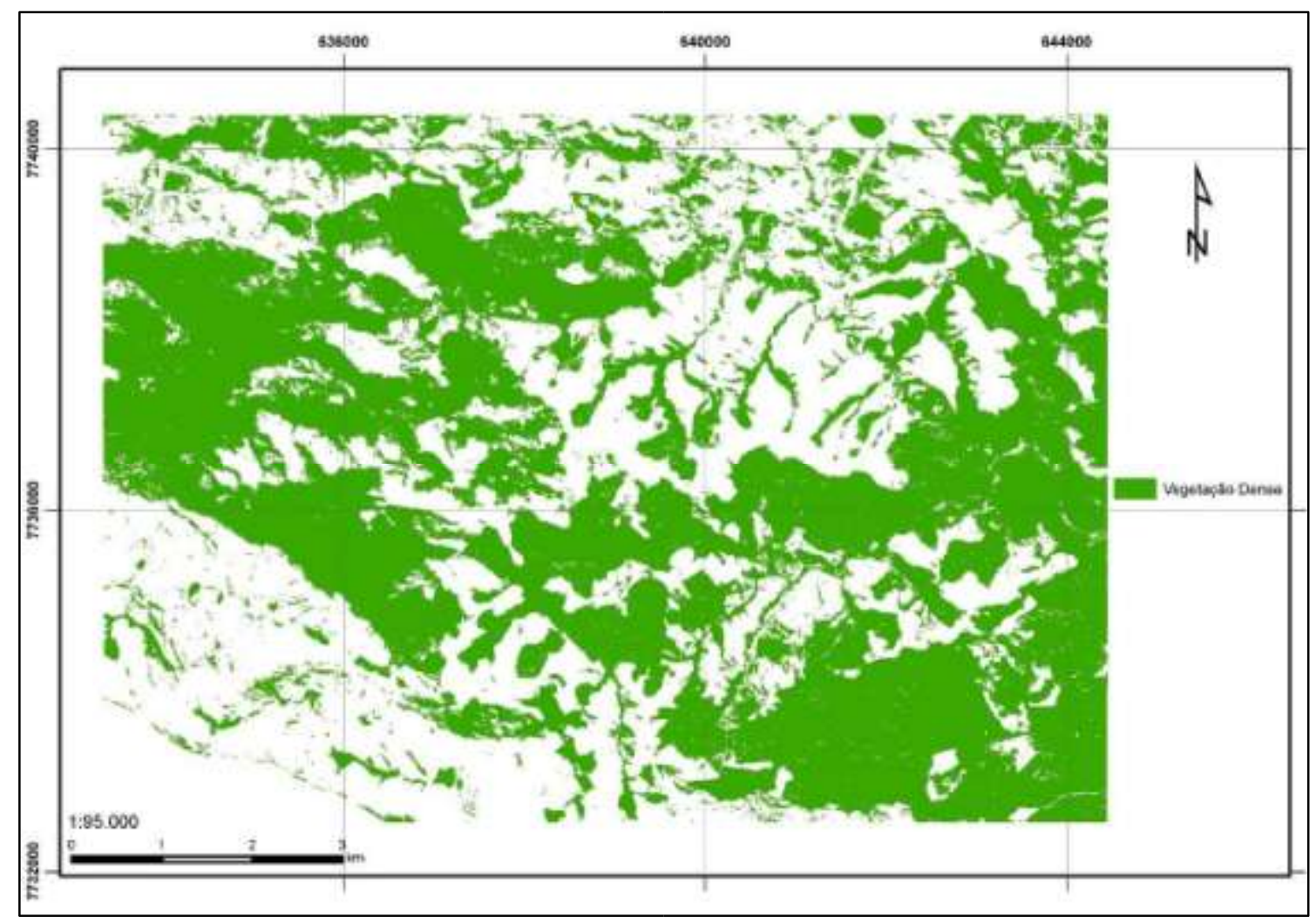

Figura 10. Classificação a partir da imagem PC2

A Figura 10 demonstra a vegetação densa identificada pela classificação da imagem por componentes principais, neste caso, considerando a PC2 em relação ao mapa base. Esta classificação apresentou similaridade em relação ao Mapa Base e foi menos influenciada pelas sombras em relação ao NDVI. Na realidade as sombras foram classificadas como vegetação densa, ocorrendo ou não esta feição nas mesmas. Visualmente, é difícil afirmar qual a maior 
precisão entre a imagem PC2 e NDVI. Todavia, a seguir estão as tabelas 10 e 11 referente a matriz de confusão, erros e acurácia da PC2 X Mapa Base.

Tabela 10. Matriz de Confusão - PC2 X Mapa Base

\begin{tabular}{cccr|cccc}
\hline \multicolumn{8}{c}{ Matria de Confusão } \\
\hline \multicolumn{4}{c}{ Pixels } & \multicolumn{4}{c}{ Percentual } \\
\hline Classe & F & NF & Total & Classe & F & NF & Total \\
F & 1572858 & 239735 & 1812593 & F & 90,1 & 13,82 & 52,08 \\
NF & 172889 & 1495078 & 1667967 & NF & 9,9 & 86,18 & 47,92 \\
Total & 1745747 & 17348133480560 & Total & 100 & 100 & 100 \\
\hline
\end{tabular}

A Tabela 10 mostra o número dos pixels e percentual dos mesmos para cada classe na matriz quadrada. Verifica-se que em relação a matriz de confusão NDVI, existe pouca diferença na classificação $\mathrm{F} / \mathrm{F}$ e em NF/NF, sendo 1,93\% e -0,73\% respectivamente. Observase que as diferença positivas para $\mathrm{F} / \mathrm{F}$ e negativa para $\mathrm{NF} / \mathrm{NF}$ se refere ao fato de uma classe aumentar e outra diminuir. Mais informações podem ser verificadas na Tabela 11.

Tabela 11. Erros e Acurácia - PC2 X Mapa Base

\begin{tabular}{ccccc}
\hline \multicolumn{5}{c}{ Erros } \\
\hline Classe & Comissão (\%) Omis & Comissão (pixel) & Omissão (pixel) \\
F & 13,23 & 9,9 & $239735 / 1812593$ & $172889 / 1745747$ \\
NF & 10,37 & 13,82 & $172889 / 1667967$ & $239735 / 1734813$ \\
\hline \multicolumn{5}{c}{ Acurácia } \\
\hline Classe & Acur. Prod.(\%) Us & uário (\%) & Acur. Prod.(pixel) & Usuário (pixel) \\
F & 90,1 & 86,77 & $1572858 / 1745747$ & $1572858 / 1812593$ \\
NF & 86,18 & 89,63 & $1495078 / 1734813$ & $1495078 / 1667967$ \\
\hline
\end{tabular}

O erro de comissão, no caso de $\mathrm{F}$, aumentou em relação ao NDVI, contudo nãoproporcionalmente. Enquanto ocorreu um aumento de 0,03\% de pixels reconhecidos pela classificação em PC2, ocorreu aumento de $0,02 \%$ nos erros. O erro de comissão em NF diminuiu $(10,37 \%)$ devido ao número de pixels reconhecidos nesta classe ter caído. Os valores dos erros de omissão e acurácia do produtor e usuário foram similares aos mostrados no NDVI. Todavia a acurácia global na classificação da imagem PC2 apresentou leve aumento e resultou em 88,14\%, uma diferença de apenas 0,6\% para a acurácia global da classificação da imagem NDVI. 
A partir das duas classificações, foi possível compará-las com o mapa base para cálculo do coeficiente de Kappa. De acordo Santos et al (2010, p. 112) apud Congalton\& Green, as classificações das imagens geradas em sensoriamento remoto são identificadas em determinados intervalos de valores, conforme níveis de aceitação. Veja a Tabela 12.

Tabela 12. Intervalo de aceitação dos resultados do índice de Kappa

\begin{tabular}{cc}
\hline Índice Kappa (K) & Característica \\
$\mathrm{K} \leq 0,4$ & Pobre \\
$0,4<\mathrm{k} \leq 0,8$ & Razoável \\
$\mathrm{K} \geq 0,8$ & Excelente \\
\hline
\end{tabular}

O resultado do índice de Kappa para a classificação NDVI em relação ao mapa basefoi de 0,7507 se classificando no nível Razoável. O resultado para a classificação PC2 em relação ao mapa base foi de 0,7629 encontrando-se também na classe Razoável.

Tendo como base as tabelas de matriz de confusão, acurácia e erros e coeficiente de Kappa, é possível afirmar que a classificação através da imagem NDVI e PC2 são similares enquanto precisão no mapeamento da vegetação densa, tendo a segundo breve êxito.

\section{6- CONCLUSÃO}

O sensoriamento remoto realmente se caracteriza como ferramenta poderosa para a classificação de feições. Os algoritmos são importantes para o reconhecimento de padrões em uma imagem de forma a facilitar o trabalho do analista que evita um trabalho maior em vetorizações extensas e interpretações incorretas. Entretanto, é necessária cautela por parte do operador no momento de analisar a saída dos dados, isto é, verificar o resultado do processo realizado e concluir se existe qualidade ou não no produto.

Em relação ao mapeamento da vegetação, a necessidade de um olhar crítico é primordial para verificação dos resultados de uma classificação. No caso deste trabalho, observou-se que o método de classificação pelas imagens NDVI e PC2 apresentaram resultados similares para o mapeamento da vegetação no fragmento de cena de alta resolução espacial usada. Todavia, esta conclusão foi baseada em métodos quantitativos de comparação que também devem ser analisados cuidadosamente para não se obter avaliações incoerentes. 
No caso do NDVI, confirmou-se a questão da dificuldade referente as sombras na imagem. $\mathrm{O}$ analista deverá ter cuidado na escolha deste método ao se trabalhar no mapeamento da vegetação em imagens que possuem relevo escarpado que ocasionam sombras e consequentemente perda de informação. Neste caso, o profissional poderá escolher outro índice que adeque melhor a realidade encontrada ou outra imagem que possua menos sombras.

Em relação a PC2, acontece o contrário ao NDVI, existe o reconhecimento de sombras como vegetação. Em determinado momento isso pode ser uma vantagem, pois onde existe ocorrência de sombra pode haver vegetação. Mas em situações contrárias, isso se caracteriza como desvantagem devido ao fato de mapear a vegetação, por exemplo, em locais que ela não está presente. Para minimizar este problema, pode-se criar uma máscara na imagem para retirar os referidos alvos (sombras, nuvens) que produzem alteração nos resultados gerados. (SOUZA et al, 2009, p. 4).

Acredita-se que os métodos de classificação de imagens estão sendo aprimorados atodo momento no intuito de se mapear com maior qualidade as feições presentes no espaço. É necessário estar ciente que os erros sempre estarão presentes, mas os mesmos devem ser trabalhados e minimizados no intuito de se buscar o tão sonhado modelo objetivo da realidade.

\section{REFERÊNCIAS BIBLIOGRÁFICAS}

www.rapideye.com.br, 2014. Acesso em: 25/11/2014.

ANTUNES, M. A. H.; SIQUEIRA, J. C. D. S. Características das imagens RapidEye para mapeamento e monitoramento e agrícola e ambiental. Anais XVI Simpósio Brasileiro de Sensoriamento Remoto, Foz do Iguaçu, 13-18 Novembro 2013. 8.

BORATTO, I. M. D. P.; GOMIDE, R. L. Aplicação dos índices de vegetação NDVI, SAVI e IAF na caracterização da cobertura vegetativa da região Norte de Minas Gerais. Anais XVI Simpósio Brasileiro de Sensoriamento Remoto, Foz do Iguaçu, 13-18 Abril 2013. 8.

CÂMARA, G. et al. SPRING: Integratingremotesensingand GIS byobject-oriented data modelling, v. 20, n. 3, p. 395-403, Maio-Junho 1996.

FLORENZANO, T. G. Iniciação em Sensoriamento Remoto. $3^{\text {a }}$. ed. São Paulo: Oficina de Textos, 2011.

JANOTH, J. et al. Procedimentos Baseados em Segmentação para a Análise de Mudanças e Classificação Florestais com Dados de Satélite de Alta Resolução. In: BLASCHKE, T.; KUX, H. Sensoriamento Remoto e SIG Avançados. 2a. ed. São Paulo: Oficina de Textos, 2007. Cap. 9, p. 303. 
MENESES, P. R.; ALMEIDA, T. D. Introdução ao Processamento de Imagens de Sensoriamento Remoto. Brasília: Universidade de Brasília, 2012.

MOURA, A. C. M. et al. Uso de imagens RapidEye como apoio à tomada de decisões no planejamento e gestão da paisagem do município de Bom Sucesso - MG. Anais XVI Simpósio Brasileiro de Sensoriamento Remoto, Foz do Iguaçu, 13-18 Abril 2013. 8.

PONZONI, F. J.; SHIMABUKURO, Y. E.; KUPLICH, T. M. Sensoriamento Remoto da Vegetação. 2a . ed. São Paulo: Oficina de Textos, 2012.

SANTOS, A. R. D.; PELUZIO, T. M. D. O. Spring 5.1.2 Passo a Passo - Aplicações Práticas. $1^{\text {a }}$. ed. Alegre:

Programa de Pós-Graduação em Ciências Florestais da UFES - PPGCF/CCA - UFES, 2010.

Disponivel em: <http://www.mundogeomatica.com.br/spring5x.htm>. Acesso em: $13 / 11 / 2014$.

SOUZA, S. F. D. et al. Utilização de análise por componentes principais (ACP) no diagnóstico das alterações da cobertura vegetal densa na bacia do rio Natuba - PE. Anais XIV Simpósio Brasileiro de Sensoriamento Remoto, Natal, 25-30 Abril 2009. 7189-7196.

SUAREZ, A. F.; CANDEIAS, A. L. B. Avaliação de acurácia de dados de sensoriamento remoto para o município de Maragogipe. IV Vimpósio Brasileiro de Ciências Geodésicas e Tecnologia da Geoinformação, Recife, 06-09 Maio 2012. 1-10.

VENTURIERI, A. Apostila do curso de introdução às técnicas de sensoriamento remoto. Belém: [s.n.], 2007. 